\title{
Estoque de carbono orgânico total e fracionamento granulométrico da matéria orgânica em sistemas de uso do solo no Cerrado
}

\author{
Total organic carbon stock and granulometric fractioning of organic matter in soil use systems in \\ Cerrado
}

\begin{abstract}
Marina Chiquito Nanzer*, Simone Cândido Ensinas, Giselle Feliciani Barbosa, Paulo Gabriel Vechetin Barreta, Taine Pereira de Oliveira, Jefferson Rogério Marques da Silva \& Leonardo Albino Paulino
\end{abstract}

Universidade Estadual de Mato Grosso do Sul, Cassilândia, MS, Brasil. *Autor para correspondência: marina_nanzer@hotmail.com.

Submissão:03/10/2017 / Aceite: 05/08/2018

\begin{abstract}
RESUMO
Os sistemas de uso do solo apresentam potencial de alterar os estoques de carbono orgânico, podendo permanecer estáveis, aumentar ou diminuir em relação à área sem interferência antrópica. Com isso, objetivou-se quantificar e comparar os estoques de carbono orgânico total, carbono orgânico associado aos minerais, carbono orgânico particulado e calcular o índice de manejo de carbono em solos cultivados sob diferentes sistemas de uso. Os tratamentos foram representados por seis sistemas de uso do solo: vegetação nativa de cerrado, seringueira solteira, seringueira consorciada com abacaxi, pastagem de Brachiaria sp. com 30 anos, pastagem de Brachiaria sp. com três anos e sistema de plantio convencional. Em cada sistema foram coletadas amostras de solo nas camadas de 0-10, 10-20 e 20-30 cm para avaliar os teores e estoques de carbono no solo, e amostras indeformadas com anéis volumétricos para estimar a densidade do solo. Os resultados foram submetidos à análise pelo teste de Scott-Knott $(p \leq 0,05)$. $O$ carbono orgânico total e as frações granulométricas da matéria orgânica mostraram ser um atributo promissor para avaliação da qualidade do solo. O carbono orgânico total, carbono orgânico particulado e carbono orgânico associado aos minerais foram superiores para vegetação nativa, pastagem de Brachiaria sp. 30 anos, seguidos pelos sistemas com seringueira. $O$ índice de manejo de carbono calculado indicou que o uso de seringueira agrega benefícios ao solo a médio e longo prazo, seguido pelo tratamento com Brachiaria sp.
\end{abstract}

PALAVRAS-CHAVE: neossolo, carbono particulado, índice de manejo de carbono.

\begin{abstract}
Soil use systems have the potential to alter organic carbon stocks and may remain stable, increase, or decrease relative to the area without anthropogenic interference. The objective of this study was to quantify and compare the total organic carbon stock, organic carbon associated with minerals, particulate organic carbon, and calculate the carbon management index in soils grown under different systems of use. The treatments were represented by six systems of soil use: native vegetation of cerrado, single rubber tree, rubber tree with pineapple, Brachiaria sp. with 30 years, a pasture of Brachiaria sp. with three years, and conventional planting system. In each system, soil samples were collected in the 0-10, 10-20 and 20$30 \mathrm{~cm}$ layers to evaluate soil carbon contents and stocks, and undisturbed samples with volumetric rings to estimate soil density. The results were analyzed by Scott-Knott test $(p \leq 0.05)$. The total organic carbon and the grain size fractions of the organic matter showed to be a promising attribute for soil quality evaluation. Total organic carbon, particulate organic carbon, and organic carbon associated with minerals were higher for native vegetation, Brachiaria sp. 30 years, followed by systems with rubber trees. The calculated carbon management index indicated that the use of rubber trees adds benefits to the soil in the medium and long term, followed by the treatment with Brachiaria sp.
\end{abstract}

KEYWORDS: neosol, particulate carbon, carbon management index.

\section{INTRODUÇÃO}

A qualidade do solo é considerada um dos fatores-chave para se alcançar a sustentabilidade de um sistema de produção, diante disso, torna-se importante estudar o efeito que o uso, o manejo e o tempo de utilização do solo promovem em seus atributos (WENDLING et al. 2005). 
Dentre os atributos do solo que podem ser utilizados para avaliar o efeito dos sistemas de uso sobre sua qualidade, destaca-se a matéria orgânica do solo (MOS). A MOS pode ser definida como uma soma de todas as substâncias orgânicas, composta por uma mescla de resíduos animais e vegetais, em diversos estádios de decomposição (SILVA \& MENDONÇA 2007). No solo sua presença é extremamente importante no fluxo de gases de efeito estufa entre a superfície terrestre e a atmosfera (LEITE et al. 2013).

O carbono representa $58 \%$ da MOS, por isso, a determinação dos teores de carbono no solo pode ser utilizada para estimar a quantidade da fração orgânica no solo. Maiores teores de MOS contribuem para melhoria da qualidade do solo, uma vez que, a MOS influência nas propriedades químicas, físicas e biológicas do solo (MIELNICZUK 2008) e o seu teor também é utilizado como indicador da qualidade dos sistemas de manejo do solo (RHEINHEIMER et al. 2008).

Tão importante quanto a determinação dos teores totais de carbono, a determinação de carbono nas frações da MOS também pode fornecer informações importantes a respeito da qualidade do solo e dos impactos dos sistemas de uso no solo. O fracionamento granulométrico da MOS consiste na separação de duas frações orgânicas: o carbono orgânico particulado (COp) e o carbono orgânico associado aos minerais (COam). O COp é a fração da MOS separada por dispersão e peneiramento do solo associada à fração areia $(\mathrm{COp}>53 \mu \mathrm{m})$, sendo caracterizado como partículas derivadas de resíduos de plantas e hifas com estrutura celulares reconhecíveis, cuja permanência no solo está condicionada à proteção física desempenhada por agregados. O COam é a fração da MOS associada às frações silte e argila do solo $(\mathrm{COam}<53 \mu \mathrm{m})$, sendo definida como a fração da MOS que interage com a superfície de partículas minerais, formando os complexos organominerais, estando protegida pelo mecanismo de proteção coloidal (LOSS et al. 2009).

A partir dos estoques de COT e de carbono nas frações da MOS é possível calcular o índice de manejo de carbono (IMC) que permite avaliar de forma conjunta o efeito dos sistemas de manejos na quantidade e qualidade da matéria orgânica do solo, contribuindo para avaliar a qualidade do solo (BLAIR et al. 1995). As estimativas do IMC são realizadas considerando um índice de estoque de carbono que relaciona o estoque do tratamento a ser avaliado com o estoque de um sistema de referência. Como referências geralmente são adotadas áreas que não sofreram alterações antrópicas, sendo estabelecido para esta área um IMC $=100$ (CONCEIÇÃO et al. 2014).

$\mathrm{Na}$ remoção da vegetação nativa para a implantação de sistemas de manejo ou cultivo tem sido observada redução na quantidade de MOS. Em vários trabalhos foram descritos que os sistemas de manejo implicaram em expressivos efeitos na qualidade dos solos tropicais e subtropicais (CUNHA et al. 2007).

Apesar da repercussão gerada, ainda não há dados conclusivos a respeito da quantidade de carbono que é liberada com a substituição da vegetação nativa por sistemas de uso do solo, nem mesmo quanto de carbono é mantido nos diversos compartimentos desse novo ambiente, principalmente se tratando do compartimento solo. Nesse caso, a substituição de ambientes naturais por agroecossistemas com culturas introduzidas causa alteração tanto na quantidade quanto na qualidade do carbono do solo (COSTA et al. 2009).

Em solos aerados, o uso de sistemas conservacionistas proporciona alterações na ciclagem de carbono no sistema solo-atmosfera, com aumento dos estoques de COT, resultante da diminuição nas taxas de decomposição da matéria orgânica (BAYER et al. 2000).

O solo manejado em SPD pode apresentar aumento dos estoques de carbono e de nitrogênio (LOVATO et al. 2004), em comparação ao sistema de preparo convencional, com aração e gradagens, que resulta na diminuição dos estoques de COT e aumento do fluxo de $\mathrm{CO}_{2}$ para a atmosfera, indicando assim que a eliminação do revolvimento do solo é uma prática importante na recuperação de solos degradados.

A utilização de pastagens em áreas degradadas de lavouras pode contribuir para a melhoria das propriedades edáficas do solo, pela presença de resíduos vegetais e raízes da pastagem. Além disso, aumenta os teores de carbono e melhora significativamente as condições de aeração e capacidade de infiltração de água, por apresentarem um sistema radicular extenso e renovado constantemente (MACEDO 2009). As gramíneas perenes, componentes das pastagens, possuem sistemas radiculares abundantes e elevada rizodeposição com distribuição uniforme de exsudatos no solo o que favorece a manutenção do teor de MOS (CARNEIRO et al. 2009). De acordo com LOVATO et al. (2004) as pastagens por possuírem sistema radicular abundante e agressivo, alocam uma maior fração do carbono, com isso serão mais eficientes em aumentar o COT do solo.

A seringueira é uma espécie que apresenta ciclo de produção longo e, portanto, com capacidade de armazenar carbono em madeira e outros tecidos até a morte e a decomposição, fase que o carbono na madeira poderá ser desprendido na forma de gás carbônico, monóxido de carbono, ou metano, ou poderá 
ficar incorporado no solo como substância orgânica (FERNANDES et al. 2007). Segundo MATIAS et al. (2012) a seringueira, assim como as demais espécies arbóreas em geral, apresenta características como alto aporte de material vegetal, que aliado ao não revolvimento do solo contribuem para o maior estoque de COT mostrando a capacidade dessa espécie florestal como mitigadora do aquecimento global, visto que atua na diminuição do $\mathrm{CO}_{2}$ presente na atmosfera.

Baseado nas informações relatadas, o presente trabalho embasa-se na hipótese de que o diferente uso do solo, determinado pelo sistema empregado, afeta a quantidade de MOS, de modo que se esperam maiores benefícios em sistemas conservacionistas de uso do solo. Neste contexto, como em Cassilândia, região Leste de Mato Grosso do Sul existe carência de informações a este respeito, objetivou-se quantificar e comparar os teores e estoques de COT, COam, COp e calcular o IMC em solos cultivados sob diferentes sistemas de uso.

\section{MATERIAL E MÉTODOS}

O estudo foi realizado em sistemas de uso do solo localizados no município de Cassilândia, MS, cujas coordenadas geográficas são $51^{\circ} 43^{\prime} 15^{\prime \prime} \mathrm{W}, 1^{\circ} 07^{\prime} 21^{\prime \prime} \mathrm{S}$ e altitude média de $520 \mathrm{~m}$, em solo classificado como Neossolo Quartzarênico Órtico (SANTOS et al. 2013) com teor de 860, 50 e $90 \mathrm{~g} \mathrm{~kg}^{-1}$ de argila, silte e areia, respectivamente. A caracterização química das áreas em estudo está apresentada na Tabela 1. $O$ clima da região é classificado segundo ALVARES et al. (2013) como clima tropical chuvoso (Aw) apresentando verão chuvoso e inverno seco com precipitação menor que $60 \mathrm{~mm}$.

Tabela 1. Propriedades químicas do solo na camada de $0-20 \mathrm{~cm}$ nos diferentes sistemas de uso provenientes de um Neossolo Quartzarênico Órtico. Cassilândia, MS, 2017.

Table 1. Chemical properties of soil from the $0-20 \mathrm{~cm}$ layer in the various systems of use coming from an Optical Quartzenetic Neosol. Cassilândia, MS, 2017.

\begin{tabular}{|c|c|c|c|c|c|c|c|c|c|c|}
\hline Trat. & $\mathrm{pH} \mathrm{CaCl}{ }_{2}$ & $\mathrm{H}+\mathrm{Al}$ & $\mathrm{Al}$ & $\mathrm{Ca}$ & $\mathrm{Mg}$ & K & $P$ & SB & CTC & $\mathrm{V}(\%)$ \\
\hline & & \multicolumn{5}{|c|}{ 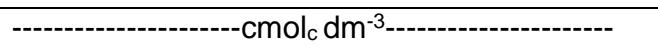 } & $\mathrm{mg} \mathrm{dm}^{-3}$ & \multicolumn{2}{|c|}{$---\mathrm{cmol}_{\mathrm{c}} \mathrm{dm}^{-3}---$} & \\
\hline$\overline{\mathrm{VN}}$ & 4,50 & 7,18 & 1,75 & 0,12 & 0,09 & 0,05 & 3,35 & 0,26 & 7,44 & 3,49 \\
\hline SG & 4,59 & 5,68 & 1,29 & 0,12 & 0,07 & 0,03 & 3,49 & 0,22 & 5,90 & 3,73 \\
\hline SCA & 4,92 & 5,37 & 1,08 & 0,40 & 0,36 & 0,12 & 5,79 & 0,88 & 6,25 & 14,08 \\
\hline PAST-30 & 5,12 & 4,23 & 0,61 & 0,58 & 0,16 & 0,05 & 6,30 & 0,79 & 5,02 & 15,74 \\
\hline PAST-3 & 5,93 & 2,89 & 0,20 & 0,82 & 0,47 & 0,10 & 14,16 & 1,39 & 4,28 & 32,48 \\
\hline PC & 5,26 & 4,25 & 0,74 & 0,71 & 0,26 & 0,10 & 18,54 & 1,07 & 5,32 & 20,11 \\
\hline
\end{tabular}

Legenda: VN = vegetação nativa, $\mathrm{SG}=$ seringueira solteira, SCA = seringueira consorciada com abacaxi), PAST-30 = pastagem com 30 anos, PAST-3 = pastagem com 3 anos e PC = sistema de plantio convencional. V (\%)= Saturação por bases; SB = Soma de bases, CTC potencial a $\mathrm{pH}=7,0=$ Capacidade de troca de cátions.

Os tratamentos foram representados por seis sistemas de uso do solo, sendo eles: vegetação nativa de cerrado (VN), seringueira solteira (Hevea brasiliensis) (SG), seringueira consorciada com abacaxi (Ananas comosus) (SCA), pastagem com 30 anos (PAST-30), pastagem com 3 anos (PAST-3) e sistema de plantio convencional (PC) (Tabela 2).

Cada sistema de uso do solo foi subdividido em quatro subáreas que corresponderam às repetições. As amostras de solo foram coletadas em cada subárea de cada sistema nas camadas de 0-10, 10-20 e 20$30 \mathrm{~cm}$. Também foram coletadas amostras indeformadas com anéis volumétricos para se estimar a densidade do solo. A densidade do solo foi utilizada no cálculo dos estoques de carbono orgânico total (COT), carbono orgânico particulado (COp) e carbono orgânico associado aos minerais (COam).

Após a coleta as amostras de solo foram destorroadas, secas à sombra e passadas em peneira de malha de $2 \mathrm{~mm}$, foi retirada uma porção da amostra de solo que foi triturada em almofariz e passada em peneira de malha de $0,210 \mathrm{~mm}$. Em seguida realizaram-se as análises para determinação do carbono orgânico total (COT).

O teor de COT foi obtido pelo método de oxidação via úmida, segundo metodologia descrita por YEOMANS \& BREMNER (1988). Para o fracionamento granulométrico da matéria orgânica do solo foi utilizada a metodologia descrita por CAMBARDELLA \& ELLIOTT (1992). O índice de manejo de carbono (IMC) foi calculado pela expressão IMC = ICC $\times$ IL $\times 100$ de acordo com a metodologia descrita por BLAIR et al. (1995). Para determinação dos estoques de COT, COp e COam foi utilizado a expressão: Estoque de 
$\mathrm{C}$ em Mg ha-1 = (Teor de carbono em $\mathrm{g} \mathrm{kg}^{-1} \mathrm{x}$ densidade do solo $\mathrm{em} \mathrm{kg} \mathrm{dm}^{-3} \mathrm{x}$ espessura da camada de solo considerada em $\mathrm{cm}) / 10$.

Tabela 2. Histórico dos sistemas de uso do solo provenientes de um Neossolo Quartzarênico Órtico. Cassilândia, MS, 2017.

Table 2. History of soil use systems from an Optical Quartzenetic Neosol. Cassilândia, MS, 2017.

\begin{tabular}{|c|c|}
\hline Sistema de Uso & Histórico da área \\
\hline Vegetação Nativa de Cerrado (VN) & $\begin{array}{l}\text { Área com vegetação natural, caracterizada como área de } \\
\text { reserva que estava separada à distância de } 300 \text { m das } \\
\text { áreas em estudo. }\end{array}$ \\
\hline Seringueira Solteira (Hevea brasiliensis) (SG) & $\begin{array}{l}\text { Área cultivada com seringueira por } 20 \text { anos sem manejo } \\
\text { da fertilidade do solo. }\end{array}$ \\
\hline $\begin{array}{l}\text { Seringueira consorciada com abacaxi (Ananas } \\
\text { comosus) (SCA) }\end{array}$ & $\begin{array}{l}\text { Área cultivada com seringueira por seis anos em } \\
\text { consórcio com abacaxi. Foi realizada aplicação de } 2 \mathrm{Mg} \\
\text { ha }^{-1} \text { de calcário na área e a adubação seguiram as } \\
\text { recomendações das culturas. }\end{array}$ \\
\hline Pastagem com 30 anos (PAST-30) & $\begin{array}{l}\text { Área cultivada com pastagem de Brachiaria brizantha cv. } \\
\text { Marandu por } 30 \text { anos sob pastejo semi-intensivo, com } \\
\text { manejo esporádico da fertilidade do solo. }\end{array}$ \\
\hline Pastagem com 3 anos (PAST-3) & $\begin{array}{l}\text { Área cultiva com pastagem de Brachiaria brizantha cv. } \\
\text { Marandu há três anos com manejo da fertilidade do solo, } \\
\text { ausência de pastejo na área. Anteriormente a área } \\
\text { estava ocupada com pastagem degradada. }\end{array}$ \\
\hline Sistema de Plantio convencional (PC) & $\begin{array}{l}\text { Área cultivada com amendoim (Arachis hypogaea) em } \\
\text { sistema de plantio convencional. Foi realizada a } \\
\text { aplicação de } 2 \mathrm{Mg} \mathrm{ha}^{-1} \text { de calcário e a adubação foi } \\
\text { realizada com } 900 \mathrm{~kg} \mathrm{ha}^{-1} \text { de } 4-14-8 \text {. As amostras foram } \\
\text { coletadas após a colheita do amendoim e a área estava } \\
\text { anteriormente ocupada com pastagem degradada. }\end{array}$ \\
\hline
\end{tabular}

O experimento foi analisado em delineamento inteiramente casualizado. Os dados foram submetidos à avaliação de normalidade de sua distribuição pelo teste de Lilliefors. Posteriormente, os resultados foram submetidos à análise de variância por meio do teste $F$, e, quando significativa, as médias dos tratamentos foram agrupadas pelo teste de Scott-Knott $(p \leq 0,05)$. Para a análise estatística utilizou-se 0 software Statistical Assistance, versão 7.7 (SILVA \& AZEVEDO 2014).

\section{RESULTADOS E DISCUSSÃO}

Os maiores teores e estoques de carbono orgânico total (COT) nas camadas de 0-10 e $10-20 \mathrm{~cm}$ foram verificados na área de vegetação nativa (VN) $\left(11,3 \mathrm{~g} \mathrm{~kg}^{-1}\right.$ e 15,9 $\left.\mathrm{Mg} \mathrm{ha}^{-1}\right)$ e pastagem de Brachiaria brizantha cv. Marandu com 30 anos (PAST-30) $\left(10,4 \mathrm{~g} \mathrm{~kg}^{-1}\right.$ e 16,3 $\left.\mathrm{Mg} \mathrm{ha}^{-1}\right)$ diferindo estatisticamente a $1 \%$ de probabilidade dos demais sistemas de uso do solo (Figura 1).

A vegetação nativa possui ausência de ação antrópica, o que proporciona um ambiente favorável à manutenção da matéria orgânica do solo (MOS) relacionada com a entrada de resíduos e pouca saída dos mesmos (GUARESCHI et al. 2012). De acordo com JAKELAITIS et al. (2008) ao estudar a qualidade da camada superficial de solo sob vegetação nativa, pastagem e áreas cultivadas constataram que os teores de COT diminuíram em função do uso do solo, de modo que, observaram os maiores teores de COT também em área de vegetação nativa. De acordo com esses autores tal constatação pode ser atribuída à maior deposição de resíduos orgânicos nos solos sob mata.

O maior teor de COT na camada de 0-20 cm também foi observado por JUNIOR et al. (2011) em áreas de cerrado em comparação a áreas sob lavoura e pastagem por 29 anos. Segundo estes autores os resultados são em decorrência do menor aporte de material na fração leve livre de carbono na camada superficial nas áreas de lavoura e pastagem.

Resultados semelhantes foram verificados por GAZOLLA et al. (2015) estudando frações da MOS sob pastagem, sistema plantio direto e integração lavoura-pecuária que constataram que os maiores valores de COT na área cerrado nativo ocorreram devido ao maior aporte de resíduos vegetais na superfície do solo, em função da vegetação presente na área, associado à ausência da ação antrópica.

$\mathrm{Na}$ camada de 20-30 cm não houve diferença entre os tratamentos para o teor de COT, já para o 
estoque de COT (EstCOT), o tratamento seringueira solteira (SG) e PAST-30 apresentaram os maiores estoques com 11 e $12,7 \mathrm{Mg} \mathrm{ha}^{-1}$, respectivamente, os quais diferiram estatisticamente a $5 \%$ de probabilidade dos demais tratamentos (Figura 1).
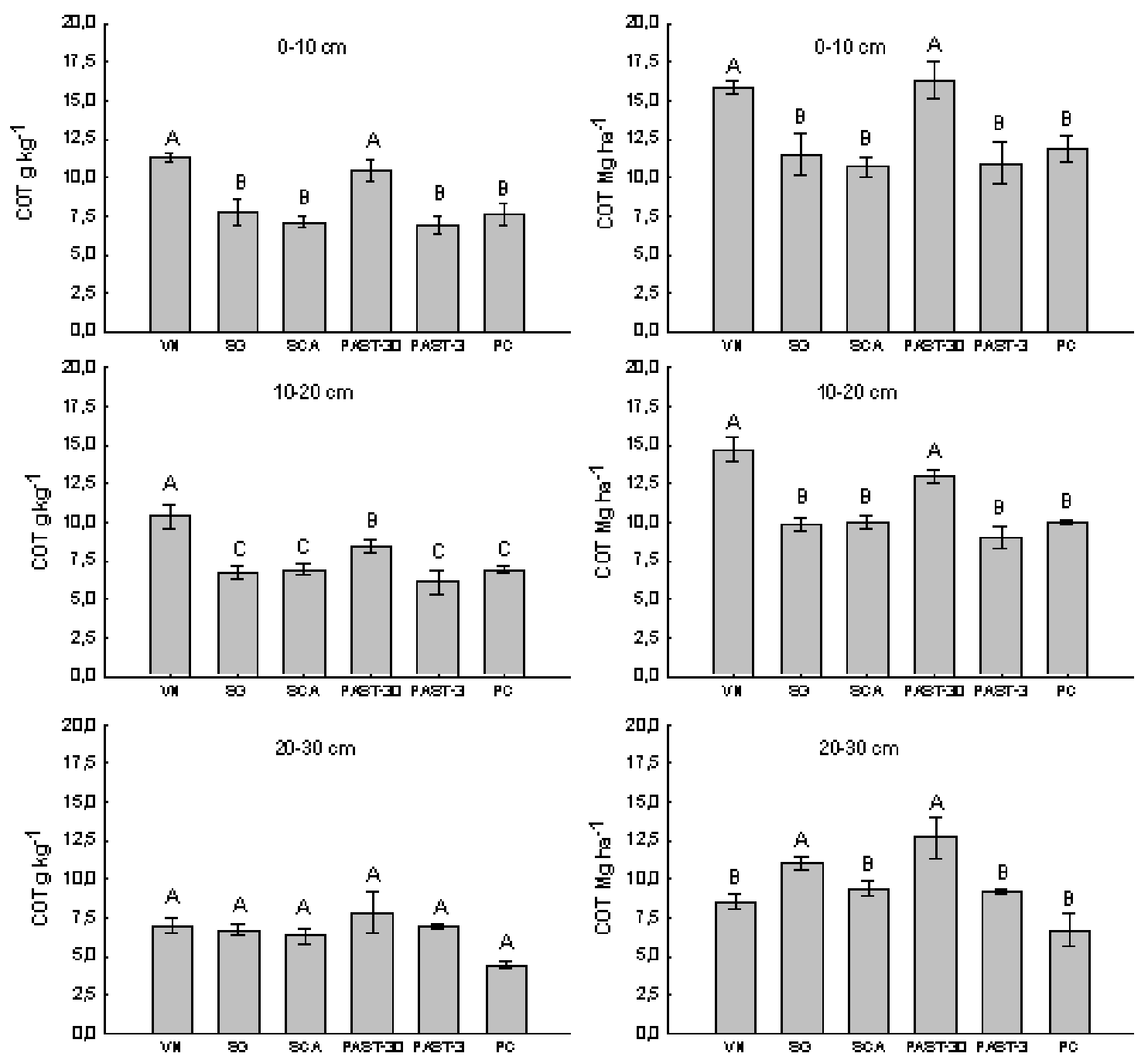

Figura 1. Teor $\left(\mathrm{g} \mathrm{kg}^{-1}\right)$ e estoque $\left(\mathrm{Mg} \mathrm{ha}^{-1}\right)$ de carbono orgânico total (COT) nas camadas de 0-10, 10-20 e 20-30 cm. Cassilândia, MS, 2017.

VN (Vegetação nativa), SG (seringueira solteira), SCA (seringueira consorciada com abacaxi), PAST-30 (pastagem com 30 anos), PAST-3 (pastagem com três anos) e PC (sistema de plantio convencional). Médias seguidas de letra iguais não diferem entre si, pelo teste de Scott-Knott $(p \leq 0,05)$. Barras representam os valores médios $(n=4) \pm$ erro-padrão da média.

Figure 1. Content $\left(\mathrm{g} \mathrm{kg}^{-1}\right)$ and stock ( $\left.\mathrm{Mg} \mathrm{ha}^{-1}\right)$ of total organic carbon (TOC) content in the layers $0-10,10-20$ and 20-30 cm. Cassilândia, MS, 2017.

VN (native vegetation), SG (single rubber tree), SCA (rubber tree intercropped with pineapple), PAST-30 (pasture at 30 years), PAST-3 (pasture at 3 years) and PC (conventional planting system). Means followed by letters of equal length do not differ from each other by Scott-Knott test $(p \leq 0.05)$. Bars represent the mean values ( $n=4 \pm$ standard error of the mean.

O benefício da PAST-30 em aumentar carbono em profundidade no solo pode ser explicado pelo sistema radicular agressivo e profundo da pastagem. Além disso, as gramíneas por serem plantas C4 contribuem para elevar e manter os aportes de carbono no solo e seu sistema radicular também aporta grande quantidade de carbono contribuindo para estabilização do carbono por aumentar o seu teor na fração mais recalcitrante do solo (BARRETO et al. 2008).

A seringueira apresenta como importantes características o alto aporte de material vegetal, assim como o não revolvimento do solo, que contribuem para o maior EstCOT mostrando a capacidade dessa espécie florestal como mitigadora do aquecimento global, visto que atua na diminuição do $\mathrm{CO}_{2}$ presente na atmosfera, fato este relatado por MATIAS et al. (2012) estudando a influência de diferentes sistemas de cultivo nos atributos físicos e no carbono orgânico do solo, constatou que o sistema de cultivo com 
seringueira apresentou maiores valores de EstCOT, o que afirma maior conservação da qualidade física do solo.

$\mathrm{Na}$ camada de 0-10 cm para o COp, os maiores teores foram apresentados no tratamento com PAST30 (3,9 $\left.\mathrm{g} \mathrm{kg}^{-1}\right)$; para o EstCOT a PAST-30 (6,3 $\left.\mathrm{Mg} \mathrm{ha}^{-1}\right)$ também apresentou os maiores estoques nesta camada, diferindo estatisticamente a $1 \%$ de probabilidade dos demais sistemas de uso do solo, porém não houve diferença significativa em relação ao sistema de plantio convencional (PC) (Figura 2).
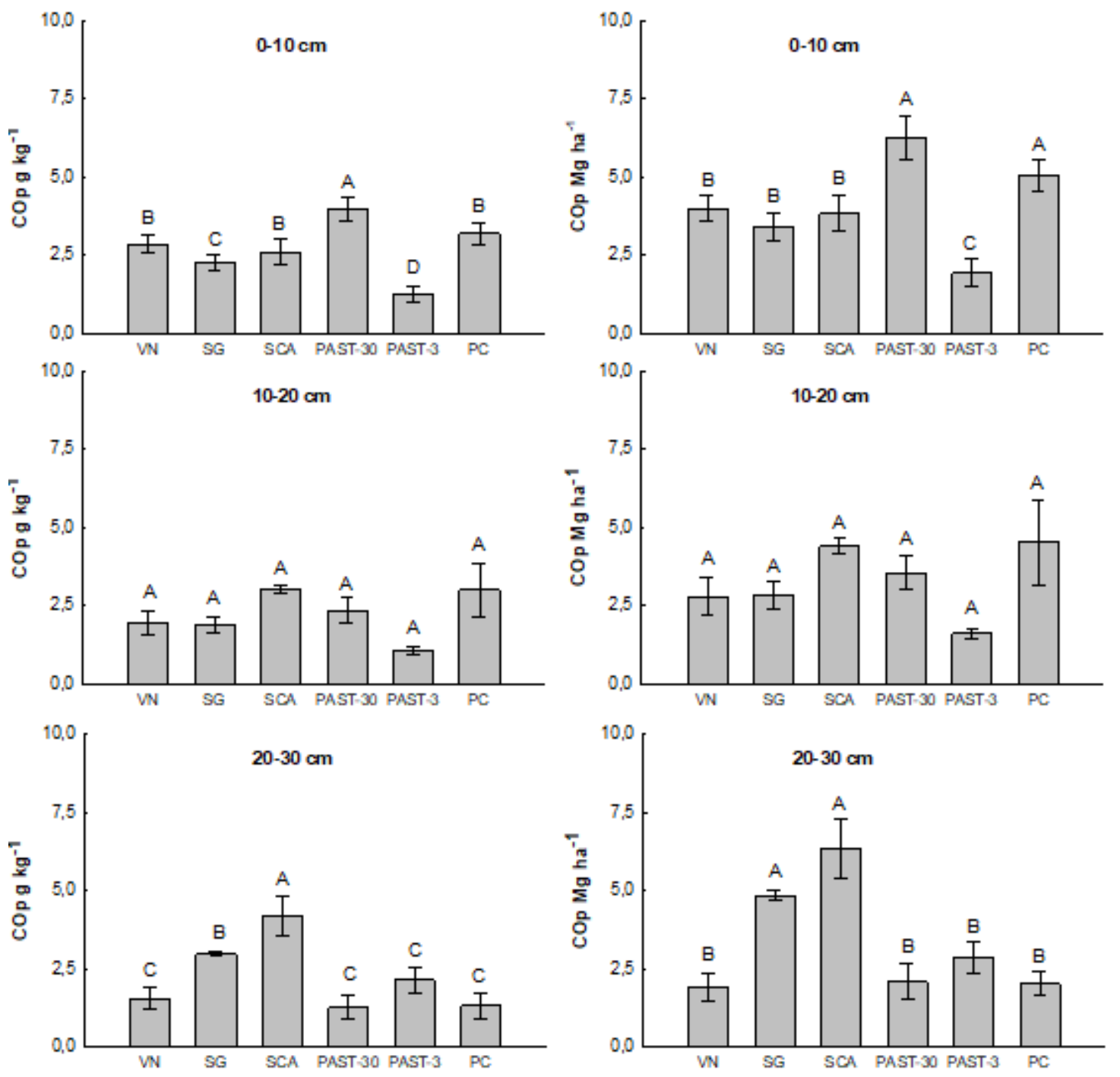

Figura 2. Teor $\left(\mathrm{g} \mathrm{kg}^{-1}\right)$ e estoque $\left(\mathrm{Mg} \mathrm{ha}^{-1}\right)$ de carbono orgânico particulado (COp) nas camadas de 0-10, 1020 e 20-30 cm. Cassilândia, MS, 2017.

VN (Vegetação nativa), SG (seringueira solteira), SCA (seringueira consorciada com abacaxi), PAST-30 (pastagem com 30 anos), PAST-3 (pastagem com três anos) e PC (sistema de plantio convencional). Médias seguidas de letra iguais não diferem entre si, pelo teste de Scott-Knott $(p \leq 0,05)$. Barras representam os valores médios $(n=4) \pm$ erro-padrão da média.

Figure 2. Content $\left(\mathrm{g} \mathrm{kg}^{-1}\right)$ and stock (Mg ha-1) of particulate organic carbon (COp) in the layers 0-10, 10-20 and 20-30 cm. Cassilândia, MS, 2017.

VN (native vegetation), SG (single rubber tree), SCA (rubber tree intercropped with pineapple), PAST-30 (pasture at 30 years), PAST-3 (pasture at three years) and PC (conventional planting system). Means followed by letters of equal length do not differ from each other by Scott-Knott test $(p \leq 0.05)$. Bars represent the mean values $(n=4) \pm$ standard error of the mean.

$\mathrm{Na}$ camada 10-20 cm não houve diferença estatística entre os tratamentos para teor e estoque de carbono. Na camada 20-30 cm houve maior teor de COp na SCA $\left(4,2 \mathrm{~g} \mathrm{~kg}^{-1}\right)$, para o estoque os maiores valores foram observados nas áreas com uso de seringueira com 6,3 $\mathrm{Mg} \mathrm{ha}^{-1}$ (Figura 3).

A manutenção dos valores de COp nos sistemas de uso do solo é dependente da capacidade de cada sistema em proporcionar maior adição de resíduos na superfície do solo, com razão $\mathrm{C} / \mathrm{N}$ e lignina/ $\mathrm{N}$ favoráveis à mineralização (FACCIN et al. 2016). De modo que, normalmente os maiores valores de COp 
são verificados na camada superficial do solo devido à maior introdução de resíduos vegetais e decomposição acentuada nesta camada.
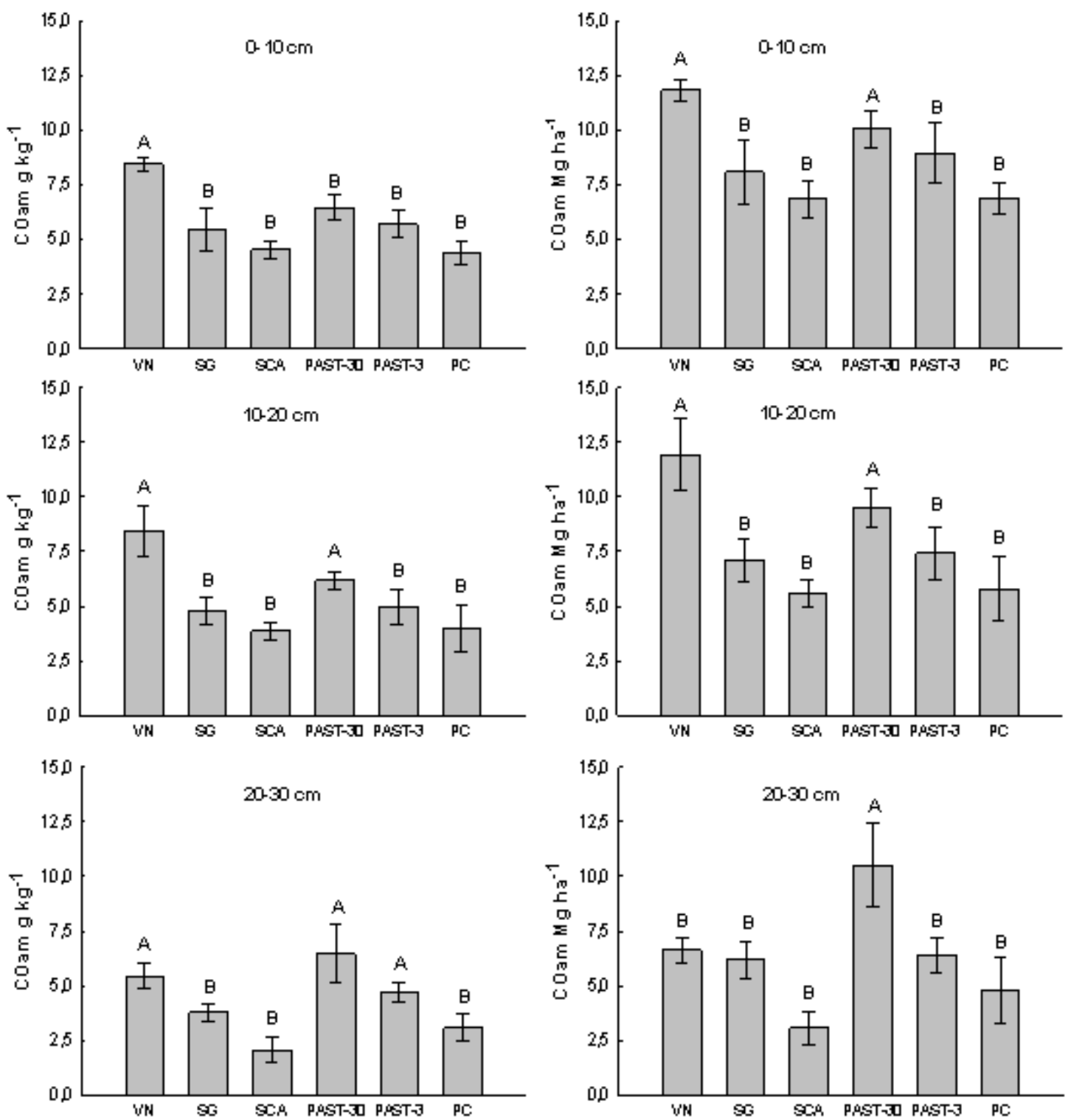

Figura 3. Teor $\left(\mathrm{g} \mathrm{kg}^{-1}\right)$ e estoque $\left(\mathrm{Mg} \mathrm{ha}^{-1}\right)$ de carbono orgânico associado aos minerais (COam) nas camadas de 0-10, 10-20 e 20-30 cm. Cassilândia, MS, 2017.

VN (Vegetação nativa), SG (seringueira solteira), SCA (seringueira consorciada com abacaxi), PAST-30 (pastagem com 30 anos), PAST-3 (pastagem com três anos) e PC (sistema de plantio convencional). Médias seguidas de letra iguais não diferem entre si, pelo teste de Scott-Knott $(\mathrm{p} \leq 0,05)$. Barras representam os valores médios $(n=4) \pm$ erro-padrão da média.

Figure 3. Content $\left(\mathrm{g} \mathrm{kg}^{-1}\right)$ and stock $\left(\mathrm{Mg} \mathrm{ha}^{-1}\right)$ carbon associated with minerals (COam) in the layers 0-10, 10-20 and 20-30 cm. Cassilândia, MS, 2017.

VN (native vegetation), SG (single rubber tree), SCA (rubber tree intercropped with pineapple), PAST-30 (pasture at 30 years), PAST-3 (pasture at three years) and PC (conventional planting system). Means followed by letters of equal length do not differ from each other by Scott-Knott test $(p \leq 0.05)$. Bars represent the mean values $(n=4) \pm$ standard error of the mean.

A superioridade da área sob PAST-30 em relação ao COp na camada superficial do solo está associada ao acúmulo de resíduos provenientes da pastagem. As gramíneas possuem sistemas radiculares abundantes e apresentam grande capacidade de liberação de exsudatos radiculares no solo, que contribuem para a manutenção dos teores de matéria orgânica (CARNEIRO et al. 2009, SILVA JÚNIOR et al. 2009).

A introdução de espécies arbóreas no sistema segundo FAVERO et al. (2008) possibilita aumento do conteúdo de COT até $25 \mathrm{~cm}$ de profundidade. Os maiores valores de COp da área de cerrado nativo em 
relação aos demais sistemas manejados na camada superficial do solo podem ser atribuídos ao seu maior teor de carbono e aporte de resíduos vegetais na superfície. Segundo LOSS et al. (2011) e ROSSI et al. (2011), sistemas de manejo e culturas que proporcionam maior aporte de carbono e resíduos na superfície do solo aumentam os teores de COp, visto que grande parte deste compartimento é formado por partículas derivadas de resíduos de plantas e está diretamente relacionado ao material vegetal recentemente adicionado ao solo.

Em relação ao COam, o tratamento VN na camada de 0-10 cm apresentou maior teor de carbono com $8,5 \mathrm{~g} \mathrm{~kg}^{-1}$, para o EstCOam, a VN também foi superior em relação aos demais tratamentos apresentando estoque de $11,9 \mathrm{Mg} \mathrm{ha}^{-1}$, no entanto não diferiu da área de PAST-30 com estoque de $10 \mathrm{Mg}$ $\mathrm{ha}^{-1}$. Comportamento semelhante também observado na camada $10-20 \mathrm{~cm}$, para teor e estoque de COam, no qual a VN e PAST-30 foram superiores aos demais tratamentos. A VN e PAST-30 proporcionaram na camada de 20-30 cm maiores valores de teor de COam com 5,5 e 6,5 g kg-1, respectivamente, porém a área de PAST-30 não diferiu na área de PAST-3. Para o EstCOam apenas a PAST-30 (10,5 Mg ha-1) foi superior aos demais tratamentos (Figura 3 ).

$\mathrm{O}$ estoque de COam isto é, aquele relacionado às frações silte e argila, normalmente é menos alterado pelas diferentes formas de manejo adotado, principalmente a curto prazo (BAYER et al. 2004). Em um sistema agroflorestal estudado por LOSS et al. (2009) foi verificado que o COam é menos afetado pelas diferentes formas de manejo adotadas, a curto prazo. Entretanto, na camada de $5-10 \mathrm{~cm}$, os resultados foram apropriados para identificar as mudanças provenientes dos sistemas de uso do solo, devido uma menor influência dos resíduos vegetais nessa camada e uma maior atuação da matéria orgânica na formação de microagregados, já que os maiores valores de COam foram observados nas coberturas com maiores teores de COT.

As gramíneas apresentam uma maior relação $\mathrm{C} / \mathrm{N}$ e lignina/ $\mathrm{N}$, o que acarretara uma decomposição mais lenta do resíduo e o que favorece o aumento dos teores de carbono ligados a argila e silte, formando complexos organominerais (SILVA \& MENDONÇA 2007). O maior conteúdo de COam no cerrado nativo ocorre pelo maior aporte de resíduos vegetais oriundos de gramíneas, segundo GAZOLLA et al. (2015).

Já os maiores valores de COam no cerrado nativo deve-se ao fato de que nesse sistema de manejo são verificados maiores teores de COT e por não ter sido submetido à revolvimento do solo, promovendo desta forma, uma maior estabilização da matéria orgânica na fração mineral. Os aumentos dos teores de cOp livre antecedem a formação de COp oclusa em macro e microagregados; por fim, há a formação de COam. Portanto, a estabilização da MOS em longo prazo se dá pelo aumento dos teores de COam, sendo importante para a manutenção de maiores teores de carbono orgânico total no solo.

MELO et al. (2016) verificaram que os menores valores de COam na área de sistema plantio convencional são decorrentes do revolvimento do solo nesse sistema de manejo, que pode acelerar a mineralização da MOS pela ruptura dos agregados e exposição desta à ação dos microrganismos. Portanto, a estabilidade da MOS fica comprometida nesse manejo. No entanto, na área de sistema de plantio direto, o padrão é inverso, em que o não revolvimento do solo, a rotação de culturas, a adubação orgânica e a manutenção dos resíduos vegetais em superfície contribuem para aumento do conteúdo de COT e promove sua maior interação com a fase mineral do solo, o que, consequentemente, aumenta a estabilidade dos agregados.

Neste trabalho, o COam representou $66,97 \%$ e o COp 33,04\% do COT. ROSSI et al. (2012) encontraram valores de COam variando entre 35 a 50\% do COT. SOUZA et al. (2008) verificaram que o COam apresentou porcentagens de 67 a $73 \%$ do COT na camada de $0-5 \mathrm{~cm}$ e de 84 a $88 \%$ na camada de $5-10 \mathrm{~cm}$. Os teores mais altos de COam estão relacionados à maior recalcitrância desta fração, o que dificulta a decomposição pelos microrganismos do solo.

$\mathrm{Na}$ camada de 0-10 cm não houve diferença estatisticamente entre os tratamentos analisados no variável índice de manejo de carbono (IMC). Para a camada $10-20 \mathrm{~cm}$ os tratamentos SG, SCA e PAST-30 foram superiores estatisticamente aos outros tratamentos. Para camada de $20-30 \mathrm{~cm}$, o tratamento SG foi significativamente superior em relação aos demais tratamentos, apresentando maior IMC (Figura 4).

Sabe-se que o IMC mede as alterações nos estoques de carbono orgânico considerando os aspectos da labilidade do carbono orgânico do solo (NICOLOSO 2005). Valores de IMC inferiores a 100 indicam práticas prejudicais a manutenção da matéria orgânica e da qualidade do solo. ROSSI et al. (2012) e GAZOLLA et al. (2015) verificam maiores IMC em sistema com utilização de Brachiaria em razão dos maiores aportes de matéria orgânica pelo sistema radicular das gramíneas. 

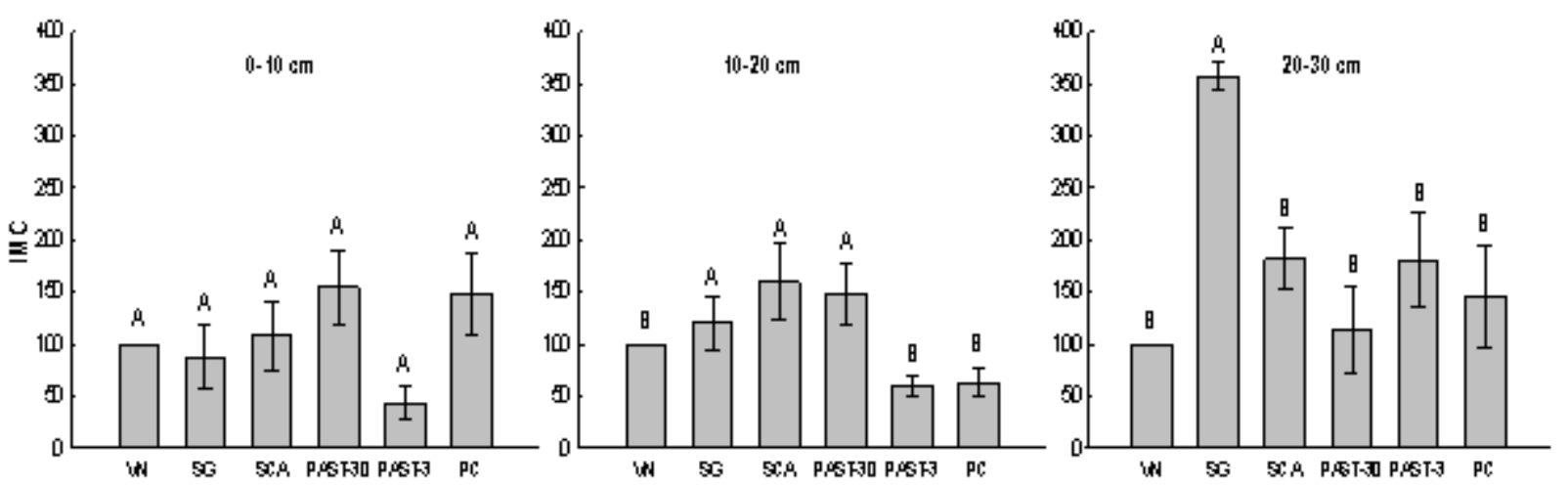

Figura 4. Índice de manejo de carbono (IMC) nas camadas de 0-10, 10-20 e 20-30 cm. Cassilândia, MS, 2017.

VN (Vegetação nativa), SG (seringueira solteira), SCA (seringueira consorciada com abacaxi), PAST-30 (pastagem com 30 anos), PAST-3 (pastagem com três anos) e PC (sistema de plantio convencional). Médias seguidas de letra iguais não diferem entre si, pelo teste de Scott-Knott $(p \leq 0,05)$. Barras representam os valores médios $(n=4) \pm$ erro-padrão da média.

Figure 4. Carbon management index (CMI) in the layers of $0-10,10-20$ and $20-30 \mathrm{~cm}$. Cassilândia, MS, 2017.

VN (native vegetation), SG (single rubber tree), SCA (rubber tree intercropped with pineapple), PAST-30 (pasture at 30 years), PAST-3 (pasture at three years) and PC (conventional planting system). Means followed by letters of equal length do not differ from each other by Scott-Knott test $(p \leq 0.05)$. Bars represent the mean values $(n=4) \pm$ standard error of the mean.

\section{CONCLUSÃO}

Os sistemas de manejo do uso de solo indicam para os atributos, carbono orgânico total, carbono orgânico particulado e carbono orgânico associado aos minerais, superioridade nos tratamentos vegetação nativa, pastagem de Brachiaria sp. com 30 anos, seguidos pelo cultivo da seringueira solteira e da seringueira consorciada com abacaxi.

O estoque de carbono orgânico total e as frações granulométricas da matéria orgânica mostraram ser um atributo promissor para avaliação da qualidade do solo.

O cálculo do IMC indicou que o uso de seringueira e pastagem de Brachiaria sp. com 30 anos agregam maiores benefícios ao solo à médio e longo prazo.

\section{REFERÊNCIAS}

ALVARES CA et al. 2013. Koppen's climate classification map for Brazil. Meteorologische Zeitschrift 22: 711-728.

BARRETO AC et al. 2008. Fracionamento químico e físico do carbono orgânico total em um solo de mata submetido a diferentes usos. Revista Brasileira de Ciência do Solo 32: 1471-1478.

BAYER C et al. 2000. Organic matter storage in a sandy clay loam Acrisol affected by tillage and cropping systems in Southern Brazil. Soil and Tillage Research 54: 101-109.

BAYER C et al. 2004. Armazenamento de carbono em frações lábeis da matéria orgânica de um Latossolo Vermelho sob plantio direto. Pesquisa Agropecuária Brasileira 39: 677-683.

BLAIR GJ et al. 1995. Soil carbon fractions, based on their degree of oxidation, and the development of a carbon management index for agricultural systems. Australian Journal of Agricultural Research 46: 1459-1466.

CAMBARDELLA CA \& ELLIOTT ET 1992. Particulate soil organic-matter changes across a grassland cultivation sequence. Soil Science Society of America Journal 56: 777-783.

CARNEIRO MAC et al. 2009. Atributos físicos, químicos e biológicos de solo de cerrado sob diferentes sistemas de uso e manejo. Revista Brasileira de Ciência do Solo 33: 147-157.

CONCEIÇÃO PC et al. 2014. Fracionamento físico da matéria orgânica e índice de manejo de carbono de um Argissolo submetido a sistemas conservacionistas de manejo. Ciência Rural 44: 794-800.

COSTA OV et al. 2009. Estoque de carbono do solo sob pastagem em área de tabuleiro costeiro no sul da Bahia. Revista Brasileira de Ciência do Solo 33: 1137-1145.

CUNHA TJF et al. 2007. Fracionamento químico da matéria orgânica e características de ácidos húmicos de solos com horizonte a antrópico da Amazônia (Terra Preta). Acta Amazônica 37: 91- 98.

FACCIN FC et al. 2016. Frações granulométricas da matéria orgânica do solo em consórcio de milho safrinha com capim-marandu sob fontes de nitrogênio. Pesquisa Agropecuária Brasileira 51: 2000-2009.

FAVERO C et al. 2008. Recuperação de área degradada com sistema agroflorestal no Vale do Rio Doce, Minas Gerais. Revista Árvore 32: 861-868.

FERNANDES TJG et al. 2007. Quantificação do carbono estocado na parte aérea e raízes de Hevea sp., aos 12 anos de idade, na Zona da Mata Mineira. Revista Árvore 31: 657-665. 
GAZOLLA PR et al. 2015. Frações da matéria orgânica do solo sob pastagem, sistema plantio direto e integração lavoura-pecuária. Semina: Ciências Agrárias 36: 693-704.

GUARESCHI RF et al. 2012. Deposição de resíduos vegetais, matéria orgânica leve, estoques de carbono e nitrogênio e fósforo remanescente sob diferentes sistemas de manejo no Cerrado goiano. Revista Brasileira de Ciência do solo 36: 909-920.

JAKELAITIS A et al. 2008. Qualidade da camada superficial de solo sob mata, pastagens e áreas cultivadas. Pesquisa Agropecuária Tropical 38: 118-127.

JUNIOR CC et al. 2011. Carbono total e $\triangle 13 \mathrm{C}$ em agregados do solo sob vegetação nativa e pastagem no bioma cerrado. Revista Brasileira de Ciência do Solo 35: 1241-1252.

LEITE LFC et al. 2013. Qualidade química do solo e dinâmica de carbono sob monocultivo e consórcio de macaúba e pastagem. Revista Brasileira Engenharia Agrícola Ambiental 17: 1257-1263.

LOSS A et al. 2009. Carbono e frações granulométricas da matéria orgânica do solo sob sistemas de produção orgânica. Ciência Rural 39: 1067-1072.

LOSS A. 2011. Dinâmica da matéria orgânica, fertilidade e agregação do solo em áreas sob diferentes sistemas de uso no cerrado goiano. Tese (Doutorado em Ciência do Solo). Rio de Janeiro: UFRRJ. 122p.

LOVATO T et al. 2004. Adição de carbono e nitrogênio e sua relação com os estoques no solo e com o rendimento do milho em sistemas de manejo. Revista Brasileira de Ciência do Solo 28: 175-187.

MACEDO MCM. 2009. Integração lavoura e pecuária: o estado da arte e inovações tecnológicas. Revista Brasileira de Zootecnia 38: 133-146.

MATIAS SSR et al. 2012. Influência de diferentes sistemas de cultivo nos atributos físicos e no carbono orgânico do solo. Revista Brasileira de Ciências Agrárias 7: 414-420.

MELO GB et al. 2016. Estoques e frações da matéria orgânica do solo sob os sistemas plantio direto e convencional de repolho. Pesquisa Agropecuária Brasileira 51: 1511-1519.

MIELNICZUK J. 2008. Matéria orgânica e sustentabilidade dos sistemas agrícolas. In: SANTOS GA et al. eds. Fundamentos da matéria orgânica do solo - ecossistemas tropicais e subtropicais. 2.ed. Porto Alegre: Metrópole. p. 1 5.

NICOLOSO RS. 2005. Dinâmica da matéria orgânica do solo em áreas de integração lavoura-pecuária sob sistema plantio direto. Dissertação (Mestrado em Ciência do Solo). Santa Maria: UFSM. 150p.

RHEINHEIMER DS et al. 2008. Comparação de métodos de determinação de carbono orgânico total no solo. Revista Brasileira de Ciência do Solo 32: 435-440.

ROSSI CQ et al. 2011. Frações húmicas da matéria orgânica do solo cultivado com soja sobre palhada de braquiária e sorgo. Bragantia 70: 622-630.

ROSSI CQ et al. 2012. Frações lábeis da matéria orgânica em sistema de cultivo com palha de braquiária e sorgo. Revista Ciência Agronômica 43: 38-46.

SANTOS HG et al. 2013. Sistema Brasileiro de Classificação de Solos. 3.ed. Brasília: EMBRAPA. 353p.

SILVA FAS \& AZEVEDO CAV. 2014. ASSISTAT software: statistical assistance. Versão 7.7 beta. Campina Grande: DEAG-CTRN-UFCG.

SILVA JÚNIOR ML et al. 2009. Carbon content in Amazonian Oxisols after Forest conversion to pasture. Revista Brasileira de Ciência do Solo 33: 1603-1611.

SILVA IR \& MENDONÇA ES. 2007. Matéria orgânica do solo. In: NOVAIS RF et al. Fertilidade do solo. Viçosa: SBCS. p. 275-374.

SOUZA ED et al. 2008. Carbono orgânico e fósforo microbiano em sistema de integração agricultura-pecuária submetido a diferentes intensidades de pastejo em plantio direto. Revista Brasileira de Ciência do Solo 32: 1273-1282.

WENDLING B et al. 2005. Carbono orgânico e estabilidade de agregados de um Latossolo Vermelho sob diferentes manejos. Pesquisa Agropecuária Brasileira 40: 487-494.

YEOMANS JC \& BREMNER JM. 1988. A rapid and precise method for routine determination of organic carbon in soil. Communications in Soil Science and Plant Analysis 19: 1467-1476. 